\title{
Evaluation of Humidity Control Ceramic Paint Using Gypsum Binder
}

\author{
Jong-Kyu Lee ${ }^{\dagger}$ and Tae-Yeon Kim \\ Energy and Environment Division Ceramics Division, Korea Institute of Ceramic Engineering and Technology, Jinju 52851, Korea
}

(Received November 8, 2017; Revised January 15, 2018; Accepted January 15, 2018)

\begin{abstract}
Active clay, bentonite and zeolite were used as porous materials for humidity controlling ceramic boards. The specific area and the pore volume of active clay were higher than those of bentonite and zeolite. It was effective to add white cement as well as a retarding agent to control the setting time of the ceramic paint. As the amount of added porous materials increases, the specific surface area and total pore volume of ceramic paint increase, but the average pore diameter decreases. The addition of porous materials having a high specific area and a large pore volume improves the moisture absorptive and desorptive performance of the ceramic paint. Therefore, in this experiment, the moisture absorptive and desorptive properties were best when active clay was added. Also, as the added amount of porous materials increases, the moisture absorptive and desorptive properties improve. In this experiment, when 70 mass\% of active clay was added to ceramic paint, the hygroscopicity was highest at about $80 \mathrm{~g} / \mathrm{m}^{2}$.
\end{abstract}

Key words : Humidity control, Setting time, Porous material, Pore volume moisture absorption and desorption

\section{Introduction}

$M$ odern societies face the serious issue of environmental pollution from population concentrations, due to rapid industrialization and urbanization resulting from economic growth. For people today, the level of comfort that an indoor space provides is important, since people spend most of their day indoors. Over time the building materials used for the indoor space have shifted from organic materials to inorganic materials, introducing hazardous properties into people's living space. Today, however, many such materials are being used in products which provide functionality beneficial to people, going beyond the simple functionality of interior materials. ${ }^{1)}$

Among the various functions of indoor construction materials, the humidity control function has recently gained attention. This focus has grown as the humidity in living environments has become problematic due to the increased sealing of structures with efforts to improve heating and cooling efficiencies and maximize energy efficiency. In particular, for vulnerable social classes who commonly live below ground or in semi-basement homes, such living conditions are causing numerous health related issues.

The appropriate humidity in residential environments ranges from $40-70 \%$ and higher humidity levels can facilitate the growth of mold and mites, and their excrement and harmful fine powder can cause allergic illnesses including asthma and atopic dermatitis., ${ }^{2,3)}$ Lower levels of humidity can increase the propagation of viruses including the com-

\footnotetext{
${ }^{\top}$ Corresponding author: Jong-Kyu Lee

E-mail : ljk25@kicet.re.kr

Tel : +82-55-792-2461 Fax : +82-55-792-2469
}

mon cold, the malfunctioning of precision equipment, ignition, deterioration of artworks and other products. Thus, humidifiers and dehumidifiers are used to maintain the appropriate humidity range. The use of such equipment requires significant energy consumption, and long term usage can cause the proliferation of various bacteria, mold, and mites inside the equipment, significantly affecting the health of people through the contamination of the environment. ${ }^{4,5)}$ Therefore, the development of a humidity controlling ceramic, which can maintain the appropriate level of humidity in a residential environment without the use of humidifiers and dehumidifiers, is becoming necessary. ${ }^{6-8)}$

Most existing humidity control ceramic products are manufactured in tile form by firing at temperatures above $1000^{\circ} \mathrm{C}$. As a reslt, these products have high manufacturing costs. The development of a low cost humidity control ceramic material is especially necessary to reduce the burden of cost that limits the improvement of the residential environments of vulnerable social classes living in basement/semi-basement dwellings, and deteriorated housing. ${ }^{9,10)}$

Therefore, in this study, a high strength gypsum binder was used along with various other porous materials to fabricate a ceramic paint utilizing room temperature curing, and the humidity characteristics were investigated.

\section{Experimental Procedure}

\subsection{Starting Material Analysis}

In this study, a non-burnable inorganic binder, rather than the conventional burnable binder, was used for the fabrication of the low cost ceramic paint. The inorganic binder used in the experiment was a high strength alpha- 
hemihydrate gypsum that underwent heat treatment at $120-140^{\circ} \mathrm{C}$ and $6-8 \mathrm{~atm}$. Also, active clay, bentonite, and zeolite were used as the porous materials. XRD was carried out for the starting materials and their chemical compositions were analyzed. BET (Model TriStar 3000 V6.02A, Micromeritics Co., USA) was used to analyze the porosity and specific surface area properties of the materials.

\subsection{Ceramic Paint Fabrication}

To fabricate the humidity control ceramic paint, high strength alpha gypsum was used as the binder along with small amounts of water and reducing, retarding, and surface strengthening agents. White cement was also added to control the strength and setting time. Active clay, bentonite, and zeolite were used as the porous materials and each were added at weight ratios of $10-70 \%$ with respect to the alpha-hemihydrate gypsum. After mixing, the raw material powder was mixed with water at a ratio of water/ powder $=0.7$. A slurry of the mixed paint was applied with varying thicknesses to the surface of cement plates. The material properties of these prepared specimens were then measured.

\subsection{Ceramic Paint Analysis}

The setting time of the fabricated paint was measured according to KS L 5103 and a Universal Testing Machine (Instron 5544, ITW Inc., USA) was used to measure the bonding strength. For the measurement of the absorptive and desorptive properties of the fabricated specimens, dried specimens with dimensions of $200 \mathrm{~mm} \times 200 \mathrm{~m}$ were stabilized until the specimens reached a constant weight at $23^{\circ} \mathrm{C}$ and $50 \%$ relative humidity conditions. Then, the specimen weights were measured, followed by another weight measurement after increasing the relative humidity to $75 \%$ and maintenance for $12 \mathrm{~h}$. After $12 \mathrm{~h}$ passed, the relative humidity was decreased to $50 \%$ and maintained for another $12 \mathrm{~h}$, then, the weights of the specimens were measured again.

This moisture absorption and desorption experiment, which involved the absorption process for the first $12 \mathrm{~h}$ then desorption for the latter $12 \mathrm{~h}$, was carried out for a total duration of $24 \mathrm{~h}$. The absorptive and desorptive properties were measured in accordance with KS F 2611. In addition, XRD and SEM analyses were conducted to analyze the microstructure characteristics of the specimens, and BET analysis was performed to analyze the pore volume and specific surface area characteristics of the specimens.

\section{Results and Discussion}

\subsection{Starting Material Properties}

For the non-burnable room temperature curing binder, a white color based gypsum binder was used after considering the various colors of products and their environmental friendliness. Generally, gypsum binders with desulfuriza-

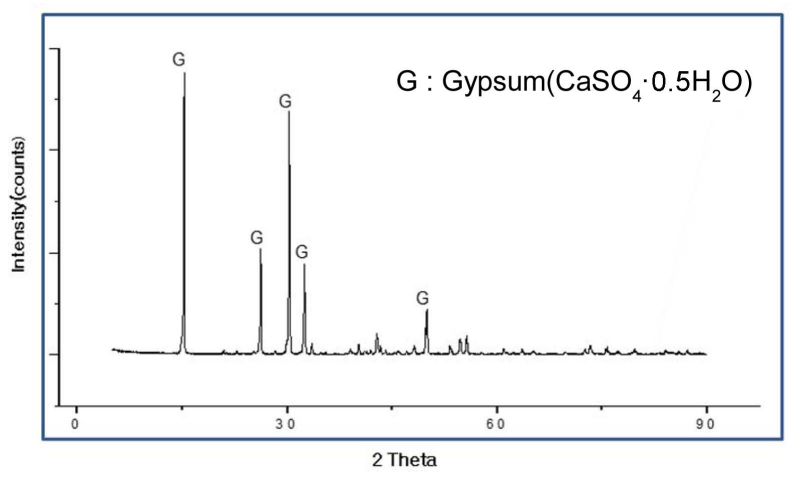

Fig. 1. XRD patterns of starting material (gypsum).

tion gypsum as the main ingredient exhibit low strength, so gypsum binders are limited by the additive amount of the porous material needed to enhance the humidity control property.

Therefore, in this study, a pressurized heat treatment method was performed and alpha-hemihydrate gypsum content above $90 \%$ was used. Fig. 1 shows the XRD result of the gypsum used in this study. It can be observed in the figure that most of the results show the diffraction peak of alpha-hemihydrate gypsum.

Additionally, active clay, bentonite, and zeolite were used as the porous materials, and Table 1 shows the chemical composition analysis results for each porous material used. The results showed that the $\mathrm{SiO}_{2}$ content was highest and $\mathrm{Al}_{2} \mathrm{O}_{3}, \mathrm{Fe}_{2} \mathrm{O}_{3}$, and $\mathrm{CaO}$ were the dominant components.

Table 2 shows the specific surface area and pore volume of the porous materials based on BET. The specific surface area of the active clay was highest at $177.95 \mathrm{~m}^{2} / \mathrm{g}$ followed by $65.36 \mathrm{~m}^{2} / \mathrm{g}$ for bentonite and $53.86 \mathrm{~m}^{2} / \mathrm{g}$ for zeolite. The pore volumes of active clay, bentonite, and zeolite $0.24 \mathrm{~cm}^{3} /$ g, $0.10 \mathrm{~cm}^{3} / \mathrm{g}$, and $0.087 \mathrm{~cm}^{3} / \mathrm{g}$, respectively. The active clay had the highest specific surface area and pore volume.

\subsection{Paint Property Analysis Depending on Mixing} Ratio

In order to procure basic data for the fabrication of the

Table 1. Chemical Composition of Starting Materials

(unit : wt\%)

\begin{tabular}{cccccccc}
\hline Materials & $\mathrm{SiO}_{2}$ & $\mathrm{Al}_{2} \mathrm{O}_{3}$ & $\mathrm{Fe}_{2} \mathrm{O}_{3}$ & $\mathrm{CaO}$ & $\mathrm{K}_{2} \mathrm{O}$ & $\mathrm{Na}_{2} \mathrm{O}$ & LOI \\
\hline Active clay & 68.36 & 11.42 & 2.64 & 1.43 & 1.06 & 1.24 & 9.02 \\
Bentonite & 55.2 & 14.80 & 9.74 & 1.82 & 1.19 & 2.38 & 10.85 \\
Zeolite & 67.2 & 12.40 & 2.92 & 2.16 & 1.48 & 1.38 & 9.27 \\
\hline
\end{tabular}

Table 2. Specific Surface Area and Total Pore Volume of Porous Materials

(unit : wt\%)

\begin{tabular}{cccc}
\hline Classification & Active Clay & Bentonite & Zeolite \\
\hline Specific surface area $\left(\mathrm{m}^{2} / \mathrm{g}\right)$ & 177.95 & 65.36 & 53.86 \\
Pore Vol. $\left(\mathrm{cm}^{3} / \mathrm{g}\right)$ & 0.24 & 0.10 & 0.087 \\
\hline
\end{tabular}




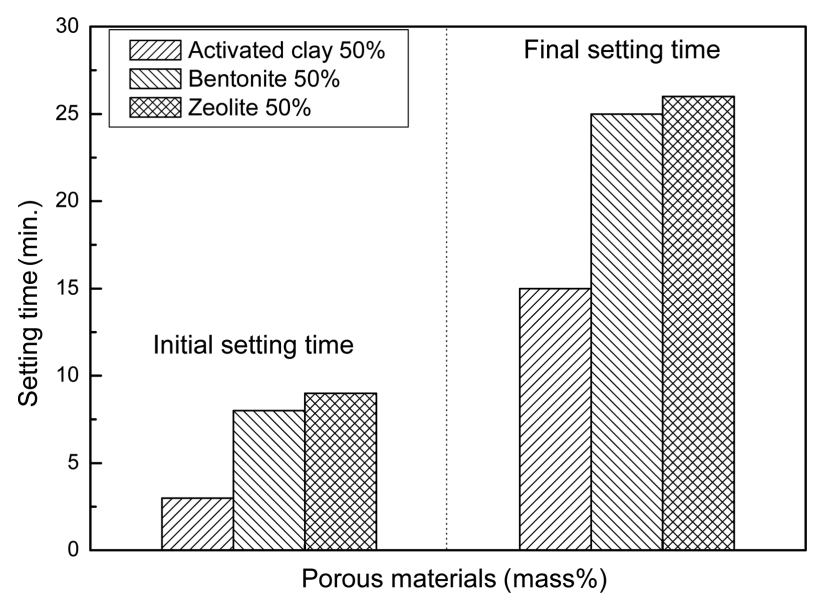

Fig. 2. Setting time with porous materials.

humidity control ceramic paint, the setting time, bonding strength, and pore characteristics were analyzed when a porous material was added to the gypsum inorganic binder. Fig. 2 shows the setting time according to the type of porous material, where the amount of added porous material was 50 mass\% (gypsum binder : porous material = $1: 1$ ). The setting time of the active clay was shortest, followed by bentonite and zeolite. This result was determined to be related to the specific surface area as shown in Table 2. When active clay with the highest specific surface area was added, the initial setting time was 3 minutes and the final setting time was 15 minutes.

Figure 3 shows the setting time when active clay with the largest specific surface area and pore volume among the porous materials was added. It was observed that the setting time decreased as the active clay addition amount increased. Active clay was predicted to have superior absorptive and desorptive characteristics because active clay has the highest specific surface area and pore volume. To utilize active clay in the paint, it is necessary to delay the setting time for improved workability.

Figure 4 shows the setting time for the borax retarding agent added to the composition with 50 mass\% added

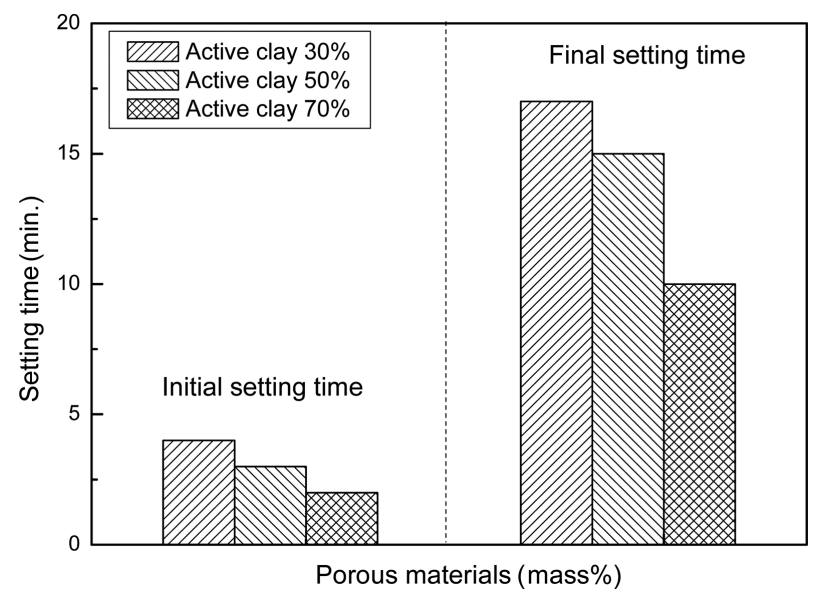

Fig. 3. Setting time with amount of active clay.

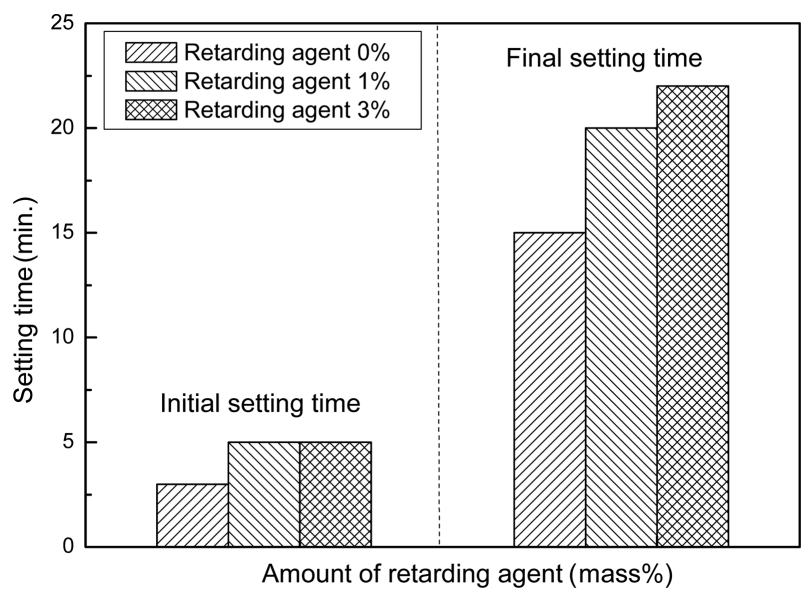

Fig. 4. Setting time with amount retarding agent.

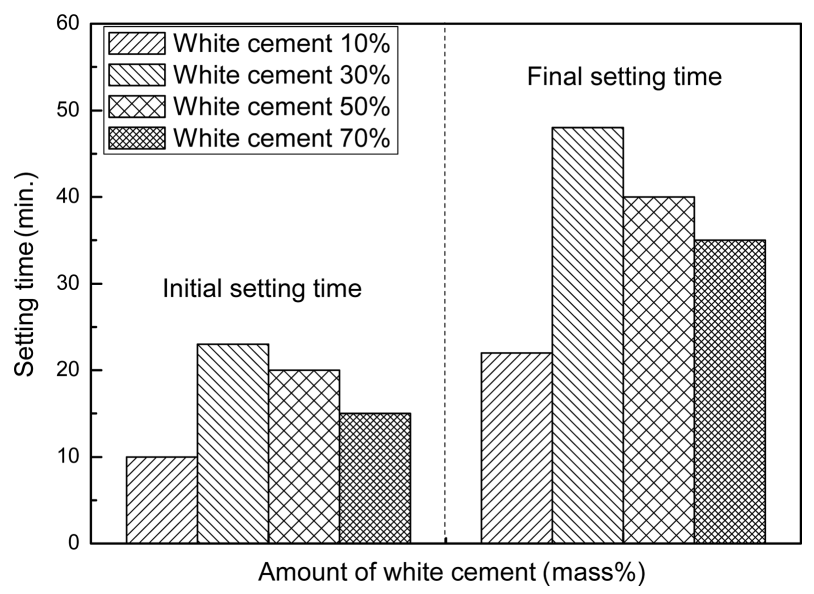

Fig. 5. Setting time with amount of white cement.

active clay (gypsum binder : active clay $=1: 1$ ), which showed the shortest setting time. It was observed that adding the retarding agent resulted in a slight increase in the setting time. When $1 \%$ retarding agent was added, the initial and final setting times were increased to 5 minutes and 22 minutes, respectively.

Figure 5 shows the initial and final setting times when white cement was added to further increase the setting time. Here, active clay was used as the porous material, and the active clay addition amount was 50 mass $\%$ with respect to the gypsum binder and white cement.

As shown in Fig. 2, the initial and final setting times when white cement was not added were around 3 minutes and 15 minutes, respectively. Adding white cement resulted in a setting time delay. With the addition of 30 mass\% white cement to the gypsum binder (gypsum binder:white cement $=7: 3$ ), the initial and final setting times were increased to 23 minutes and 48 minutes. When the addition amount was greater than 50 mass\%, the setting time slightly decreased. Thus, for the convenience of the paint application, there is a need to delay the setting time and the method of appropriately adding white cement was found to be effective. 


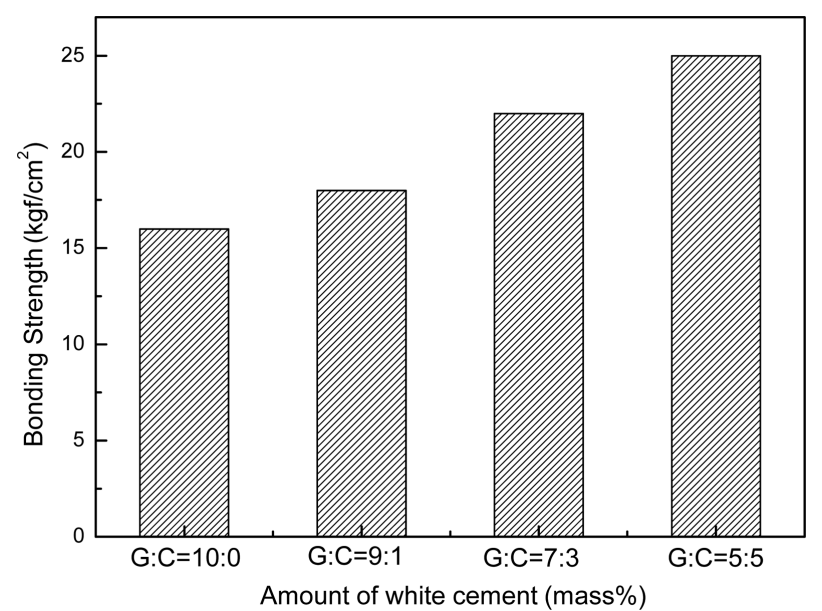

Fig. 6. Bonding strength with amount of white cement.

The bonding strength of the paint is an important property for application as a humidity control paint. In this experiment, white cement was used to control the setting time and improve the bonding strength. Fig. 6 shows the paint bonding strengths for the cases of 0 mass\% (gypsum binder : white cement $=10: 0$ ), 10 mass\% (gypsum binder : white cement $=9: 1$ ), 30 mass $\%$ (gypsum binder : white cement $=7: 3$ ), and 50 mass\% (gypsum binder : white cement $=5: 5$ ) of white cement to the gypsum binder. Here, active clay was added as the porous material at 50 mass\% with respect to the total binder.

Adding the white cement resulted in an increase in the bonding strength. The bonding strength was about $16 \mathrm{kgf} /$ $\mathrm{cm}^{2}$ when no white cement was added, while the bonding strength increased to about $25 \mathrm{kgf} / \mathrm{cm}^{2}$ when white cement was added at 50 mass\%.

\subsection{Absorptive and Desorptive Properties and Micro- structure of the Paint}

Figure 7 shows the XRD results for 30 mass\%, 50 mass\%, and 70 mass $\%$ addition of active clay with respect to the gypsum binder in the humidity control ceramic paint. The figure also includes the SEM imaging result for the 50 mass\% active clay addition case. Among the porous materials, an $\mathrm{SiO}_{2}$ peak was observed, and the result mostly showed dihydrate gypsum peaks produced by the reaction between water and the hemihydrate gypsum. Also, the intensity of the dihydrate gypsum peak was observed to decrease in peak intensity as the active clay addition amount increased. The SEM result revealed needle shape (rod type) dihydrate gypsum.

Figure 8 shows the BET analysis result for the active clay addition amount case, which exhibited the highest specific surface area and total pore volume in the humidity control ceramic paint using the gypsum binder. The specific surface area was $32.11 \mathrm{~m}^{2} / \mathrm{g}$ for 10 mass\% active clay and $135.22 \mathrm{~m}^{2} / \mathrm{g}$ for 70 mass\% active clay, showing that the specific surface area of the fabricated pain increased as the active clay content increased. Moreover, the total pore vol-
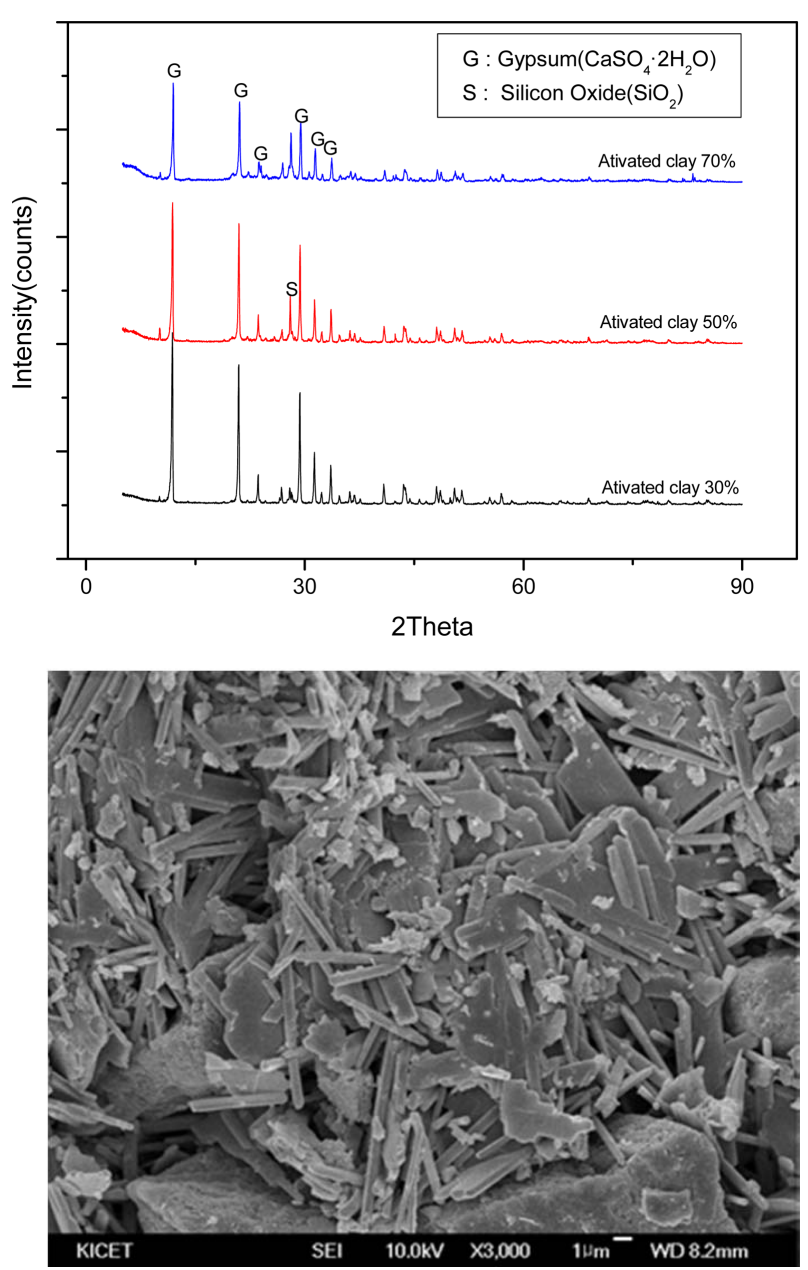

Fig. 7. XRD patterns and SEM photograph with porous materials.

ume also increased as the active clay content increased. The total pore volume was highest at $0.178 \mathrm{~cm}^{3} / \mathrm{g}$ for 70 mass $\%$ active clay content. However, the average pore size was $82.21 \AA$ for the 10 mass\% active clay content case, $63.41 \AA$ for 30 mass\%, $55.36 \AA$ for 50 mass\%, and $52.53 \AA$ for 70 mass $\%$. The average pore size decreased as the active clay content increased.

Figure 9 shows the absorptive and desorptive properties for the 50 mass\% active clay added gypsum binder case (gypsum binder : active clay $=1: 1$ ) according to the paint coating thickness. As the coating thickness increased, the absorptive and desorptive performance improved. While the absorptive and desorptive properties did not exceed 60 $\mathrm{g} / \mathrm{m}^{2}$ for paint coating thicknesses below $3 \mathrm{~mm}$, the absorptive and desorptive properties were approximately $70 \mathrm{~g} / \mathrm{m}^{2}$ for a coating thickness of $3 \mathrm{~mm}$.

Figure 10 shows the absorptive and desorptive characteristics of the ceramic paint when the active clay content was varied from 10 mass\%, 30 mass\%, 50 mass\%, to 70 mass $\%$ with respect to the gypsum binder, for the active clay with the highest specific surface area and pore volume shown in Fig. 8. Here, the paint coating thickness was set to $3 \mathrm{~mm}$. 

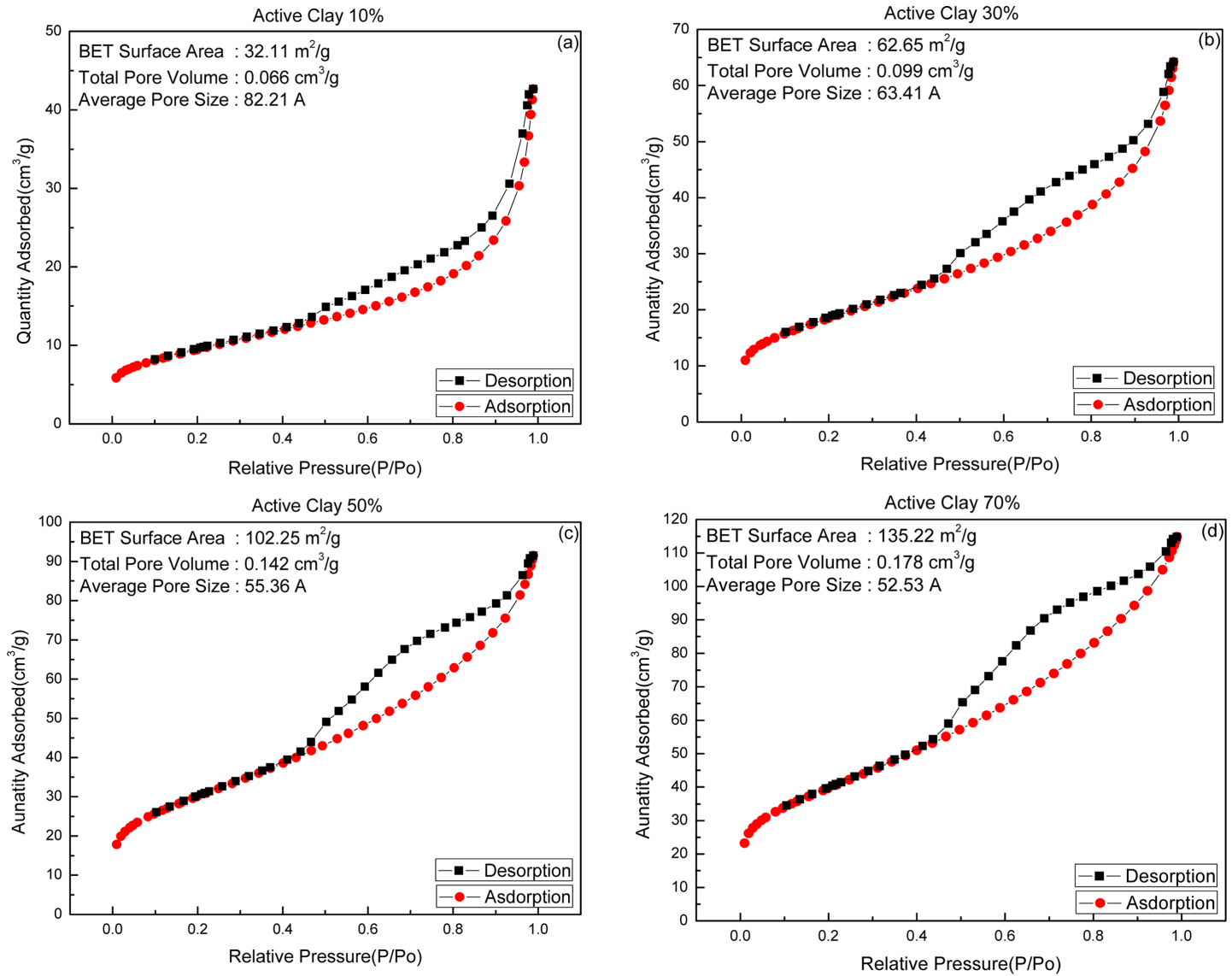

Fig. 8. BET hysteresis curve with amount of active clay. (a) active clay 10 mass\% (b) active clay 30 mass\%. (c) active clay 50 mass\% (d) active clay 70 mass\%

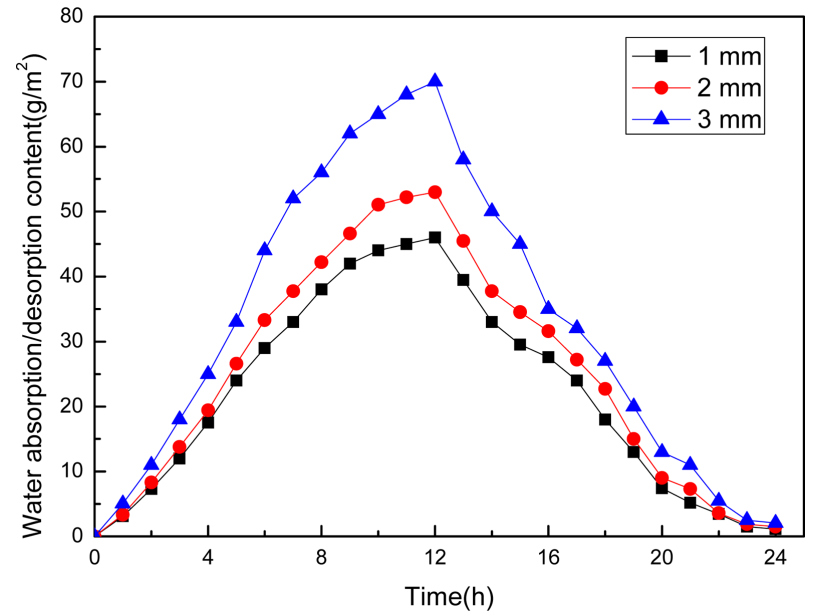

Fig. 9. Moisture absorption and desorption of ceramic paint with coating thickness.

As the active clay content increased, it was observed that the absorption and desorption amounts increased. The moisture absorption performances for the active clay addition contents of 10 mass $\%, 30$ mass $\%, 50$ mass $\%$, and 70 mass $\%$ were around $43 \mathrm{~g} / \mathrm{m}^{2}, 59 \mathrm{~g} / \mathrm{m}^{2}, 70 \mathrm{~g} / \mathrm{m}^{2}$, and $80 \mathrm{~g} / \mathrm{m}^{2}$. The paint with the 70 mass $\%$ active clay content showed the highest absorptive and desorptive performance.

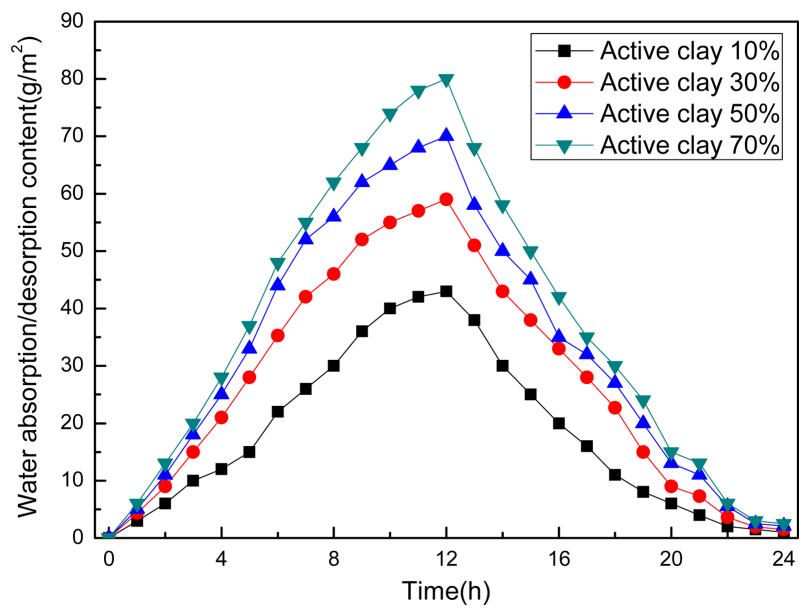

Fig. 10. Moisture absorption and desorption of ceramic paint with amount of active clay.

\section{Conclusions}

In this study, high strength alpha-hemihydrate gypsum was used as a binder for ceramic paint, and the material properties and absorptive and desorptive properties were analyzed when a significant amount of porous material was added. The following conclusions were obtained. 
The specific surface area of the added porous materials was highest for active clay followed by bentonite and zeolite, and the same order was observed for the pore volume. Since the setting time of the gypsum binder is short, using white cement in addition to a retarding agent was effective at improving the paint's workability. The absorptive and desorptive property of the ceramic paint was found to improve as the coating thickness increased, and the absorptive and desorptive performance also increased as the porous material addition amount increased. The moisture absorption performance for active clay contents of 10 mass $\%, 30$ mass\%, 50 mass\%, and 70 mass\% were around $43 \mathrm{~g} / \mathrm{m}^{2}, 59 \mathrm{~g} / \mathrm{m}^{2}, 70 \mathrm{~g} / \mathrm{m}^{2}$, and $80 \mathrm{~g} / \mathrm{m}^{2}$. The $70 \mathrm{mass} \%$ active clay addition amount case showed the highest absorptive and desorptive performance.

\section{Acknowledgments}

This research was supported by Research Program To Solve Social Issues of the National Research Foundation of Korea (NRF) funded by the Ministry of Science and ICT. (grant number).

\section{REFERENCES}

1. S. H. Sim and Y. S. Kim, "Characterization and Assessment of Indoor Air Quality in Newly Constructed Apartment-Volatile Organic Compounds and Formaldehyde," Korean J. Environ. Health Sci., 32 [4] 275-81 (2006).

2. S. K. Pang, W. J. Cho, and T. Y. Sohn, "Characteristics of VOCs Emission According Interior Finish Materials and
Working Phases of New Apartment," Korean J. Air Cond. Refrig. Eng., 18 [6] 486-92 (2006).

3. Y. J. Choi, H. S. Shim, and H. C. Shin, "The Concentration Variation of Volatile Organic Compounds before and after Renovation in Apartment Houses," J. Korean Hous. Assoc., 18 [4] 59-67 (2007).

4. D. H. Vu, K. S. Wang, B. H. Bac, and B. X. Nam, "Humidity Control Materials Prepared from Diatomite and Volcanic Ash," Constr. Build. Mater., 38 1066-72 (2013).

5. Z. Hu, S. Zheng, M. Jia, X. Dong, and Z. Sun, "Preparation and Characterization of Novel Diatomite/Ground Calcium Carbonate Composite Humidity Control Material," Adv. Powder Technol., 28 [5] 1372-81 (2017).

6. J. Zheng, J. Shi, Q. Ma, X. Dai, and Z. Chen, "Experimental Study on Humidity Control Performance of DiatomiteBased Building Materials," Appl. Therm. Eng., 114 45056 (2017).

7. M. Masanori, "A Trend Technology of Construction Paint with Hygroscopic Characteristics," Constr. Technol., 29 40-3 (2003).

8. Y. S. Chu and C. W. Kwon, "Hygroscopic Characteristic of Hydrothermal Reacted Panels Using Porous Materials," J. Korean Ceram. Soc., 45 [12] 832-38 (2008).

9. D. H. Im, Y. S. Chu, H. Song, and J. K. Lee, "Formaldehyde Adsorption and Physical Characteristics of Hydrothermal Reacted Panels Using Porous Materials," J. Korean Ceram. Soc., 46 [6] 627-32 (2009).

10. E. J. Jeong, J. K. Lee, D. S. Cheong, Y. S. Chu, and H. Song, "Hygroscopic Characteristic of Gypsum Boards Using Porous Materials," Korean J. Mater. Res., 19 [10] 538-43 (2009). 